\title{
Un acto de memoria, o el día que defendimos a Goya como un dictador sanitario.
}

\author{
An act of memory, or the day we defended Goya as a healthcare \\ dictator.
}

\section{Roberto Herrero García}

Recibido 31/08/2020 Revisado 09/10/2020

Universidad Complutense de Madrid roherrer@ucm.es
Aceptado 09/10/2020 Publicado 30/04/2021

\section{Resumen:}

Durante la actual pandemia de SARS-CoV-2 distintas voces han coincidido en el uso de términos y expresiones de carácter bélico. Pero... ¿Hablamos de una anécdota o acaso hay algún tipo de motivación que explique el uso de esta lógica marcial a la hora de referirse a una crisis sanitaria? Y, si así fuese, ¿es nuevo este fenómeno?

Para responder a estas cuestiones proponemos el estudio de la polifacética (y polémica) figura del periodista y crítico artístico Eugenio Noel (1885-1936). Un autor gracias al cual podremos ver cómo los discursos higienistas del siglo XIX y XX hicieron uso de un lenguaje médico en el que abundaban las referencias militares y autoritarias, así como la influencia decisiva que tuvieron estas mismas ideas en el devenir del mundo artístico europeo del siglo XX (especialmente en lo que se refiere a la aparición de estilos como la pintura y escultura fascistas).

Esta revisión del pasado nos permitirá hacer un ejercicio de memoria, que nos ayude a entender nuestro presente más inmediato e interrogarnos sobre nuestra responsabilidad como investigadores y artistas.

\section{Abstract:}

Throughout the current SARS-CoV-2 pandemic, different voices have insisted on the use of terms and expressions with a military origin. But... Are we talking about an anecdote or is there some kind of justification that explains the use of this military logic while referring to a health crisis? And, if that was the case, is this something new?

\section{Sugerencias para citar este artículo,}

Herrero García, Roberto (2021). Un acto de memoria, o el día que defendimos a Goya como un dictador sanitario. Tercio Creciente (Monográfico extraordinario V), (pp. 7-15), https://dx.doi.org/10.17561/rtc.extra5.5718

HERRERO GARCÍA, ROBERTO. Un acto de memoria, o el día que defendimos a Goya como un dictador sanitario. Tercio Creciente (Monográfico extraordinario V) abril 2021, pp. 7-15, https://dx.doi.org/10.17561/rtc.extra5.5718 
In order to answer these questions we propose the study of the multi-faceted (and polemical) figure of the journalist and art critic Eugenio Noel (1885-1936). An author through whom we can see how the hygienist discourses from the 19th and 20th century used a medical language in which abounded war and authoritarian references. Furthermore, we can also see the decisive influence that these same ideas had on the development of the European artistic world in the 20th century (especially in relation to the appearance of styles such as the fascist painting and sculpture).

This review of the past will allow us to carry out an exercise of memory, which will help us to understand our present and to question ourselves about our responsibility as researchers and artists.

\section{Palabras Clave:}

SARS-CoV-2, biopolítica; regeneracionismo; Eugenio Noel; Investigación Artística

\section{Key words:}

SARS-CoV-2; biopolitics; Eugenio-Noel; artistic-research

Sugerencias para citar este artículo,

Herrero García, Roberto (2021). Un acto de memoria, o el día que defendimos a Goya como un dictador sanitario. Tercio Creciente (Monográfico extraordinario V), (pp. 7-15), https://dx.doi.org/10.17561/rtc.extra5.5718

HERRERO GARCÍA, ROBERTO. Un acto de memoria, o el día que defendimos a Goya como un dictador sanitario. Tercio Creciente (Monográfico extraordinario V) abril 2021, pp. 7-15, https://dx.doi.org/10.17561/rtc.extra5.5718 
Guerra, guerra fría, escenario de posguerra, héroes y heroínas, todos somos soldados, un enemigo común, un enemigo invisible, hospital de campaña, ejército, fuerzas militares...

Estas son algunas de las expresiones o términos que se han repetido a lo largo de la actual pandemia del SARS-CoV-2. También hemos podido ver cómo han ido aumentando las tensiones geopolíticas entre Estados Unidos y China o cómo se han hecho llamamientos a la defensa de la patria a través del uso de banderas e himnos. En definitiva, una visión militarista ha dominado la imagen de la crisis sanitaria.

Pero esta forma de hablar sobre una enfermedad como si de una guerra se tratase no es algo nuevo, ni es algo que nazca con el coronavirus. Hablamos de lógicas que vienen siendo usadas desde el siglo XIX, que han protagonizado otras epidemias - como la de gripe de 19181919- y que han tenido una importante influencia en el campo artístico.

Mi propósito en este artículo es hacer una breve revisión de las influencias y consecuencias que tuvieron estos discursos en el campo artístico español. Para ello, tomaré como estudio de caso a la figura de Eugenio Noel, un periodista, ensayista y conferencianteperformativo de comienzos del siglo XX.

Este autor ha sido reivindicado por algunos trabajos como una suerte de feroz antitaurino (Codina, 2018) e, incluso, como un antecedente de las teorías de la apropiación cultural (de la Cruz, 2019). Es cierto que Noel criticó la tauromaquia y que sus trabajos se centraron en las manifestaciones populares. Pero no es menos cierto que reducir su figura a estas lecturas supone incurrir en anacronismos e, incluso, en una amnesia selectiva que blanquea algunos de los puntos más controvertidos de su figura. Para entender el pensamiento de Noel debemos quitarnos las gafas del siglo XXI y adentrarnos en las lógicas del cambio del siglo XIX al XX, un momento caracterizado por su profundo pesimismo.

Desde la década de 1870 la idea de pertenecer a una civilización en decadencia venía obsesionando a varias naciones de Europa (Campos Marín et al., 2000, p. 197). Como destaca Nerea Aresti (2014), este sentimiento surgía como consecuencia de importantes bochornos bélicos, entre los que se encontraban la derrota de la nación francesa en Sedán (1870), el ultimátum británico a Portugal (1890), la humillación italiana en la Batalla de Adua (1896) y, por supuesto, la pérdida de las colonias españolas de ultramar en el conocido como Desastre del 98. Unos conflictos en los que Francia, Portugal, Italia y España habían sentido perder su influencia internacional, a la vez que vieron cómo crecía y se asentaba el poder de las regiones anglosajonas, germanas y eslavas. 
Aunque este tipo de cambios de hegemonía han sido constantes a lo largo de la historia, la novedad de este momento fue que dicho proceso fue explicado bajo las premisas del higienismo-social. La idea consistía en que el declive político, económico y militar de algunos países era consecuencia de un debilitamiento físico e intelectual de su población fruto de las malas condiciones sanitarias de estos territorios (Campos Marín et al., 2000, p. 198).

Estas ideas higiénico-sociales inspiraron la retórica y los discursos de otras disciplinas. En el caso español, tuvieron un gran impacto en las propuestas de un grupo de pensadores de la España finisecular conocidos como los regeneracionistas. Para estos autores el concepto de enfermedad tenía un sentido mucho más amplio al puramente biológico. El debilitamiento de la población se debía a un continuo proceso en el que se habían violado las leyes de la selección natural, al fomentar "el gobierno y dirección de los mejores por los peores" (Costa, 1901, p. 30). Para Joaquín Costa, máximo representante de este movimiento, las clases superiores españolas eran un sol negro que oscurecían en sus tinieblas a una población de la que ya no podían salir más que desperdicios sociales. Como solución defendía el ejercicio de una "política quirúrgica" (1901, p. 61). Un programa de gobierno que habría de ser aplicado por una especie de dictador sanitario, el "Cirujano de Hierro", quien habría de recorrer la península:

Blandiendo su maza para limpiar la tierra de monstruos, para extirpar la vieja monarquía absoluta, refugiada en los caciques y oligarcas y en sus miserables instrumentos, siguiéndolos [sic] hasta lo más oculto de sus madrigueras y sacándolos á la luz para aplastarlos como alimañas (1914, p. 48).

En la estela del regeneracionismo, Eugenio Noel hizo una lectura de la decadencia de la nación española en términos culturales y a través de su particular crítica artística. A su entender, los males que enfermaban y que habían terminado por devorar las energías de la población irradiaban de costumbres populares como el flamenco, el cuplé, la zarzuela, la pornografía y, sobre todo, la tauromaquia. Espectáculos a los que se refería bajo el término de flamenquismo. Una categoría estética que aglutinaba todas aquellas expresiones opuestas a la "divina idea" que debía ser el arte (Noel, 1914e, pp. 8-9).

Así pues, sus críticas antitaurinas y culturales se centraban en todos los efectos nocivos que estos espectáculos podían tener sobre la población. Para Noel, el torero era un embaucador, un suicida vestido de lentejuelas que no luchaba cuerpo a cuerpo, sino que ganaba a través de piruetas, ornamentos y engaños. La plaza de toros era una especie de escuela de la corrupción donde se propagaba el hábito de ser un fanfarrón, de "capotear las circunstancias" y de escalar socialmente a través del engaño (Noel, 1914c, p. 6). De la misma forma, otros espectáculos, como el cante y el baile flamencos, eran censurados por su carácter frenético, convulsivo e histérico (Noel, 1913, p. 121). 
Noel se encargó de intentar viralizar sus ideas publicándolas en distintos periódicos, revistas y libros. Aunque aquello que le llevó a convertirse en un fenómeno de masas fue su campaña de conferencias a lo largo de todo el país. En su texto Escenas y andanzas de la campaña antiflamenca (1913), podemos ver cómo la presencia de este autor despertaba un enorme alboroto en los pueblos por los que viajaba. Desorden que él mismo potenciaba buscando despertar un componente irracional en sus charlas. Unas veces, ganándose el afecto del público y, otras, buscando su indignación a través de continuas provocaciones.

Esta importancia de la conferencia en la labor de Noel era deudora de su interés por la predicación religiosa. Noel había pasado tres años de su infancia preparándose para ser misionero y, aunque el resto de su vida fue un ferviente anticlerical, consideró de provecho el uso de las estrategias de promoción religiosa (Noel, 1914f, p. 6). Como resultado ideó un tipo de conferencia performativa, un "predicamento laico" en sus propias palabras, que tenía como fin seducir a la gente y arrojarla a la acción (1913, p. VIII).

En parte debido a esta fascinación por las técnicas de márketing religioso, Noel acabaría interesado en el poder que tenían las imágenes para comunicarse con un pueblo mayoritariamente analfabeto (1914a, p. 1). De esta forma, acabaría otorgando un papel fundamental al uso de estampas, fotografías y pastiches. Pues a su entender, solo la representación crítica y cruel de España podía permitir que esta se conociese así misma (1914d, p. 9).

Desde una perspectiva médico-social, Noel defendía que las imágenes tenían la capacidad de mostrar a la nación sus afecciones de la misma forma que los cartones de la Facultad de Medicina exponían las enfermedades de las personas (1914a, p. 1). Ésto llevó a que Noel otorgase a los pintores la tarea de diagnosticar y reflejar en sus lienzos los estigmas de la patria. Cometido que, a sus ojos, había sido emprendido con compromiso férreo por el artista Ignacio Zuloaga. Así dirá:

No sé de pintor alguno que haya comprendido mejor que Zuloaga su Patria y su tiempo. [...] Ignacio Zuloaga se encontró con una España ciega, sorda y loca, con un País imbécil sin concepto alguno de la responsabilidad ante la Historia y sin creer otra cosa que en los misterios raros por los que habia [sic] logrado su ruina y su ignorancia. [...] Entonces Zuloaga pintó. Indomable, recio, fuerte, dueño de sí mismo [...] A veces la ironía salta como un tigre al lienzo, clava sus uñas en las figuras y rasga, raspa, araña, rae, borra, tuerce y se place en ello hasta angustiarnos. (1914b, p. 2). 
También creyó encontrar un antecedente de esta misión en la obra de Francisco de Goya. Para Noel, Los desastres de la guerra y los Caprichos equivalían a los capítulos de un tratado de medicina en los que el pintor aragonés había conseguido abrir en canal y diseccionar a una nación "que se podría como una fruta muy madura" (1914b, p. 2). De hecho, llegó a la desconcertante conclusión de que Goya había sido la personalidad que más se había acercado a los valores prototípicos del dictador-sanitario de Costa, del "Cirujano de Hierro" (1914e, p. 16).

Otro aspecto que caracterizó el discurso artístico de Noel fue su nostálgica defensa del ideal escultórico de la Grecia Antigua. Gran parte del material gráfico que contenían las revistas que editó versaba sobre este tipo de estatuaria. Ilustraciones que muchas veces utilizaba de forma sentenciosa para contraponer la "serenidad" y "gracia" de las obras clásicas con la "lubricidad" y "degeneración" que atribuía al toreo y al flamenco (1914a, pp. 8-9). Tampoco faltaron las alabanzas para aquellos artistas que, como Rodin o Julio Antonio, estuvieran recuperando las fórmulas del arte monumental (1914c, p. 12).

Cabe decir que estas reivindicaciones de Noel entraban en consonancia con los caminos que tomaría el mundo artístico europeo desde la década de 1915. Momento en el que artistas como Picasso, Derain, Carrà y Servini, comenzaron a abandonar la experimentación de las vanguardias para centrarse en la vuelta al uso de un lenguaje clasicista. Un retorno al orden, como fue denominado, que traía de la mano la recuperación de los modos convencionales de representación pictórica y la idealización de los monumentos tradicionales de la historia del arte (Buchloh, 2004).

Asimismo, la defensa de la escultura clásica por parte de Noel también participaba de una visión ético-estética en la cual la forma bella se equiparaba con la vitalidad, la rectitud y la justicia. En sus propias palabras:

Las estatuas sirven para enseñarnos que la proporción en las formas es la armonía del espíritu, una promesa casi cierta de salud, una como predestinación al bien. Porque así como de un hombre que canta, parece que no puede esperarse nada malo, así de la perfección física, parece emanar la perfección moral (1914c, p. 10).

Esta postura se explica, en parte, por el papel que otorgaron los regeneracionistas a la educación física en su proyecto de rehabilitación nacional. Costa, por ejemplo, se oponía al sedentarismo debilitante y apostaba por un programa pedagógico en el que la disciplina física fuese la valedora de la formación del carácter y la moral (1979, p. 40). Siguiendo estas ideas, Noel defendía la construcción de gimnasios, estadios y termas (1914e, pp. 2-3). Lugares que permitirían el cultivo y el aseo del cuerpo. 
Pero esta apología del organismo sano venía directamente asociada al rechazo de la forma fea, grosera y repelente. Lo que en el campo social equivalía a que se repudiara, hasta la pura fobia, el cuerpo abyecto. No solo ya el organismo enfermo, sino también del cuerpo errático y racializado. En este sentido, el historiador Benjamin Buchloh (2004) ha defendido que el proceso de recuperación de las formas clásicas por parte del mundo artístico de comienzos del siglo XX allanó la aparición de las formas autoritarias propias del fascismo y del nazismo (p. 56). Algo que queda expuesto de forma manifiesta con la participación de Marinetti, ideólogo del futurismo, en la escritura del manifiesto fascista (Gompertz, 2013, pp. 176-177).

En el caso de Noel, sus teorías estuvieron sesgadas por un duro racismo antigitano. En sus escritos, el pueblo gitano aparecía estigmatizado como una raza inferior, sin sensibilidad al dolor y sin inteligencia (1916, pp. 226-227). Eran también señalados como los causantes de "nuestra muerte moral y civil", así como del nefasto devenir del arte (1913, p. 249). Retórica nada inocente, pues, pocos años antes, el doctor Enrique D. Madrazo había sugerido la total erradicación de esta comunidad como parte de su propuesta para la recuperación y perfeccionamiento biológico del Estado (Moreno Mengíbar \& Vázquez García, 1998, p. 209).

El racismo de Noel, su defensa de una ortodoxia artística monumental y sus alusiones dictatoriales nos recuerdan a algunos de los capítulos más oscuros del siglo XX. Pero es necesario aclarar que este periodista fue un autor vinculado al republicanismo, que citaba con frecuencia al periódico El Socialista y que sentía admiración por la figura de Francisco Ferrer (Noel, 1913, pp. 38-44). No hablamos, por tanto, de un reaccionario. Sino, en todo caso, de un autor ligado al progresismo español.

Es por eso que muchos acercamientos a su figura prefieren olvidar algunos de los datos más peliagudos de su ideario. No obstante, considero que estas contradicciones son particularmente interesantes y útiles. Ellas nos ayudan a ver cómo algunos de los presupuestos que más brutales consecuencias tuvieron en el siglo pasado eran entendidos como ideológicamente asépticos y fueron compartidos por la mayor parte de las posturas políticas (Moreno Mengíbar \& Vázquez García, 1998, p. 209). Además, nos ayudan a cuestionar la aparente neutralidad política de las prácticas artísticas.

Creo conveniente iniciar este tipo de revisiones críticas. Porque si los discursos que hoy rodean al Coronavirus resuenan en nuestros oídos como ecos de algo que ya fue dicho en otro tiempo, escarbar en el foso del pasado no es sino una forma de interrogar nuestro presente. 


\section{Referencias}

Aresti, N. (2014). A la nación por la masculinidad. Una mirada de género a la crisis del 98. En M. Nash (Ed.), Feminidades y masculinidades: Arquetipos y prácticas de género (pp. 47-77). Alianza Editorial.

Buchloh, B. H. D. (2004). Figuras de la autoridad, claves de la regresión. Notas sobre el retorno de la figuración en la pintura europea. En C. del. Olmo \& César. Rendueles (Trads.), Formalismo e historicidad: Modelos y métodos en el arte del siglo XX (pp. 55-85). Akal.

Campos Marín, Ricardo., Huertas, Rafael., \& Martínez Pérez, José. (2000). Los ilegales de la naturaleza: Medicina y degeneracionismo en la España de la Restauración (18761923). Consejo Superior de Investigaciones Científicas.

Codina, J. I. (2018). El pensamiento antitaurino en España, de la ilustración del XVIII hasta la actualidad [Tesis doctoral, Universitat de les Illes Balears]. https://tinyurl.com/yxa5zxpm

Costa, J. (1901). Oligarquía y caciquismo como la forma actual de gobierno en España: Urgencia y modo de cambiarla. Establecimiento Tipográfico de Fortanet.

Costa, J. (1914). Política Quirúrgica. Biblioteca Costa.

Costa, J. (1979). Oligarquía y caciquismo, Colectivismo agrario y otros escritos (antología) (R. Pérez de la Dehesa, Ed.; [4a. ed.].). Alianza.

de la Cruz, L. (2019, agosto 29). Eugenio Noel y el antiflamenquismo, ¿antecedente de la teoría de la apropiación cultural? eldiario.es. https://tinyurl.com/y6tdundu

Gompertz, W. (2013). ¿Qué estás mirando?: 150 años de arte moderno en un abrir y cerrar de ojos (F. Corriente Basús, Trad.; 1a ed.). Taurus.

Moreno Mengíbar, A., \& Vázquez García, F. (1998, abril). Crisis nacional, eugenesia y regeneracionismo biológico en España, 1898-1936. GADES, Cádiz.

Noel, E. (1913). Escenas y andanzas de la campaña antiflamenca. F. Sempere y Compañía, Editores.

Noel, E. (1914a, abril 12). El Flamenco.

Noel, E. (1914b, abril 19). El Flamenco.

Noel, E. (1914c, abril 26). El Flamenco.

Noel, E. (1914d, mayo 24). El Chispero. 
Revista de Estudios en Sociedad, Artes y Gestión Cultural

Extraordinario $V$

Abril 2021

ISSN: 2340-9096

https://doi.org/10.17561/rtc.extra5.5718

(6) 0

Noel, E. (1914e, mayo 31). El Chispero.

Noel, E. (1914f, junio 7). El Chispero.

Noel, E. (1916). Señoritos chulos, fenómenos, gitanos y flamencos. Renacimiento.. 
